\title{
AS RECENTES TENDÊNCIAS NO MERCADO IMOBILIÁRIO COSTARRIQUENHO
}

\section{THE RECENT TENDENCIES OF THE COSTA RICAN REAL-ESTATE MARKET}

\author{
SabrineAcosta Schnell ${ }^{1}$ \\ ${ }^{1}$ Universidad de Costa Rica (UCR), San José, Costa Rica e Université Sorbonne Nouvelle, Paris, França
}

Recebido em: 9 jan. 2015 | Aceito em: 2 fev. 2016

\section{RESUMO}

A cidade de San José, Costa Rica está passando por transformações significativas vinculadas às inovações técnicas na área da construção civil, mudanças na legislação e a imposição de uma nova forma de morar. A intensificação da urbanização resultou na vertiginosa verticalização em pontos estratégicos da Gran Área Metropolitana. Este artigo apresenta temas sobre as tendências recentes do mercado imobiliário, destacando os principais fatores que contribuem e limitam o desenvolvimento imobiliário local. Também se observam os diferentes atores e métodos de financiamento que participam no setor imobiliário. Discutem-se as diferenças entre valor de uso e valor de troca destes recentes empreendimentos residenciais e como a localização influi nesta diferença.

Palavras-chave: Urbanização; Mercado imobiliário; Crédito; Financiamento imobiliário; Costa Rica.

\section{ABSTRACT}

San Jose, Costa Rica is undergoing significant changes related to the technical innovation in the area of construction, changes in legislation and the imposition of a new way of living. The intensification of urbanization led to the fast residential verticalization in strategic points of the Gran Área Metropolitana. This article presents the recent trends in the housing market, highlighting key factors that contribute and limit the local real estate development. It is also analysed the different agents and financing methods involved in the housing sector. It is discussed the differences between use value and exchange value of these recent residential projects and how location influences this differences.

Keywords: Urbanization; Real estate market; Credit; Real estate financing; Costa Rica.

\section{INTRODUÇÃO}

Atualmente as cidades costarriquenhas estão passando por transformações significativas vinculadas às inovações técnicas na área da construção civil e na imposição de uma nova forma de morar. Na capital San José a intensificação da urbanização nos inícios do século XXI resultou na vertiginosa verticalização em pontos estratégicos da Gran Área Metropolitana (GAM) (Figuras 1 e 2). 


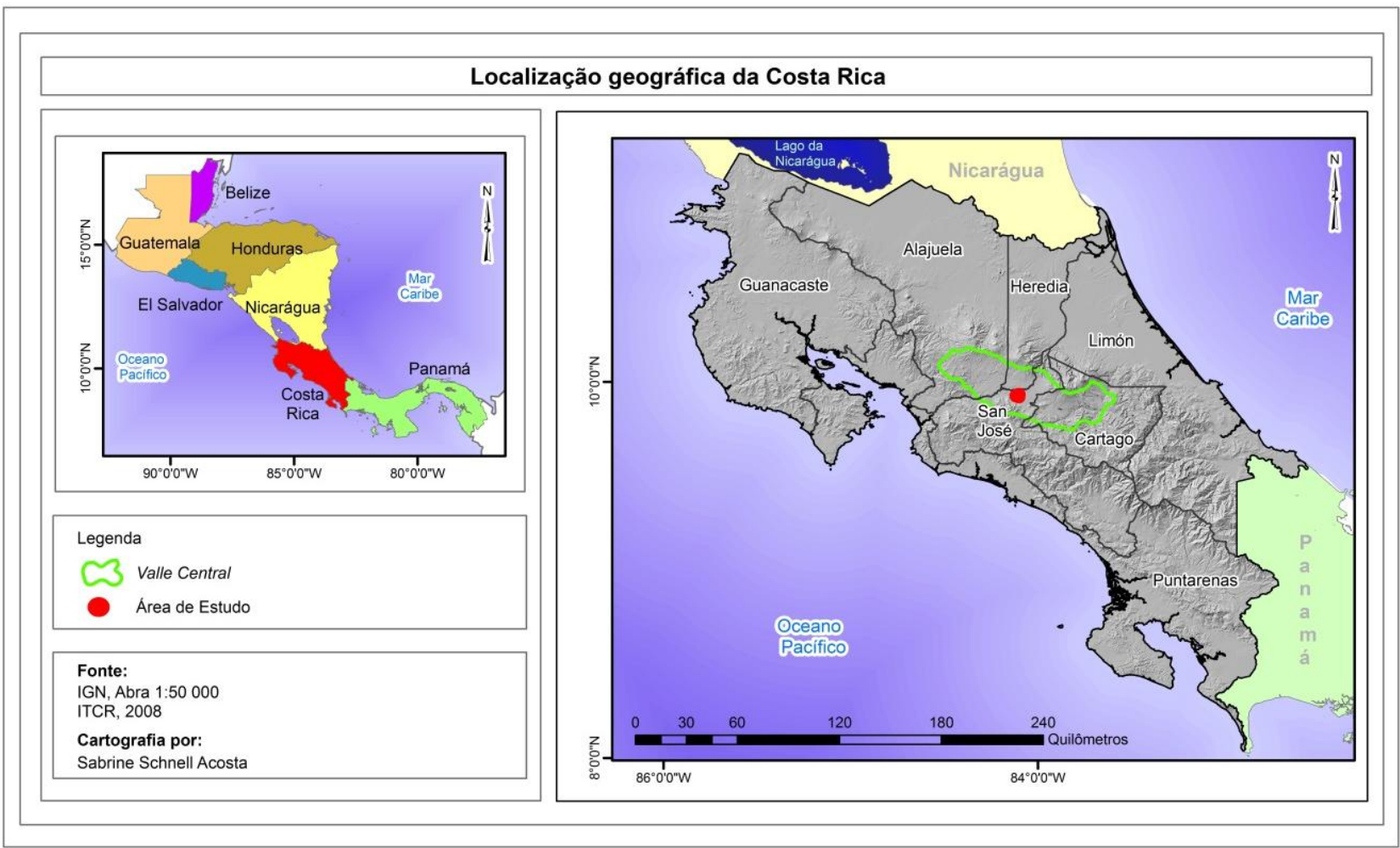

Figura 1. Localização geográfica da Costa Rica



Figura2. Arredores do Parque Metropolitano La Sabana e os cinco distritos centrais de San José 
Este artigo apresentará as recentes tendências do mercado imobiliário. Também se observará como as flutuações na economia mundial afetam o desenvolvimento dos investimentos no setor imobiliário. Entre as tendências desvendadas, apresentar-se-ão as diferenças entre valor de uso e valor de troca destes empreendimentos. Discutir-se-á como a localização exerce uma grande influência na determinação dos preços da moradia e como esta renda diferencial é paga pelos indivíduos ou empresas em vista do superfaturamento que a localização privilegiada lhes proporciona.

Igualmente se discutirá sobre os principais fatores que contribuem e limitam o desenvolvimento imobiliário local incluindo a utilização da natureza como mercadoria no processo de publicidade imobiliária. Este tema se analisará aproximando distantes temporalidades com o intuito de desvendar a especificidade do local.

\section{Tendências recentes do desenvolvimento do mercado imobiliário costarriquenho}

O mercado imobiliário costarriquenho tem passado por processos de transformação onde se pode enfatizar o auge da construção de moradias na GAM durante a primeira década do século XXI. De maneira paralela as mudanças na GAM, as novas propostas imobiliárias no litoral Pacífico Central e Pacífico Norte também têm contribuído com diversas transformações no mercado. Estas propostas incluem hotéis de diferentes tipos com diversos serviços e também segundas moradias, de alto padrão, focadas especificamente a estrangeiros. Em geral, as tendências do setor imobiliário se refletem em uma dinamização dos setores produtivos diretamente envolvidos na produção dos edifícios, uma disponibilidade de mercado e uma alteração na estrutura fundiária. (SOUZA, 1994).

Em ambos gráficos 1 e 2 se observa como o número de construções residenciais aumentou entre 2002 até 2007 e uma das características do ano 2005 foi o incremento na construção de moradias em condomínios. Cabe ressaltar também que a partir de 2008 a quantidade de área construída (Figura 3) sofreu uma queda considerável, o que também se observa especificamente no número de construções residenciais. (Figura 4). 


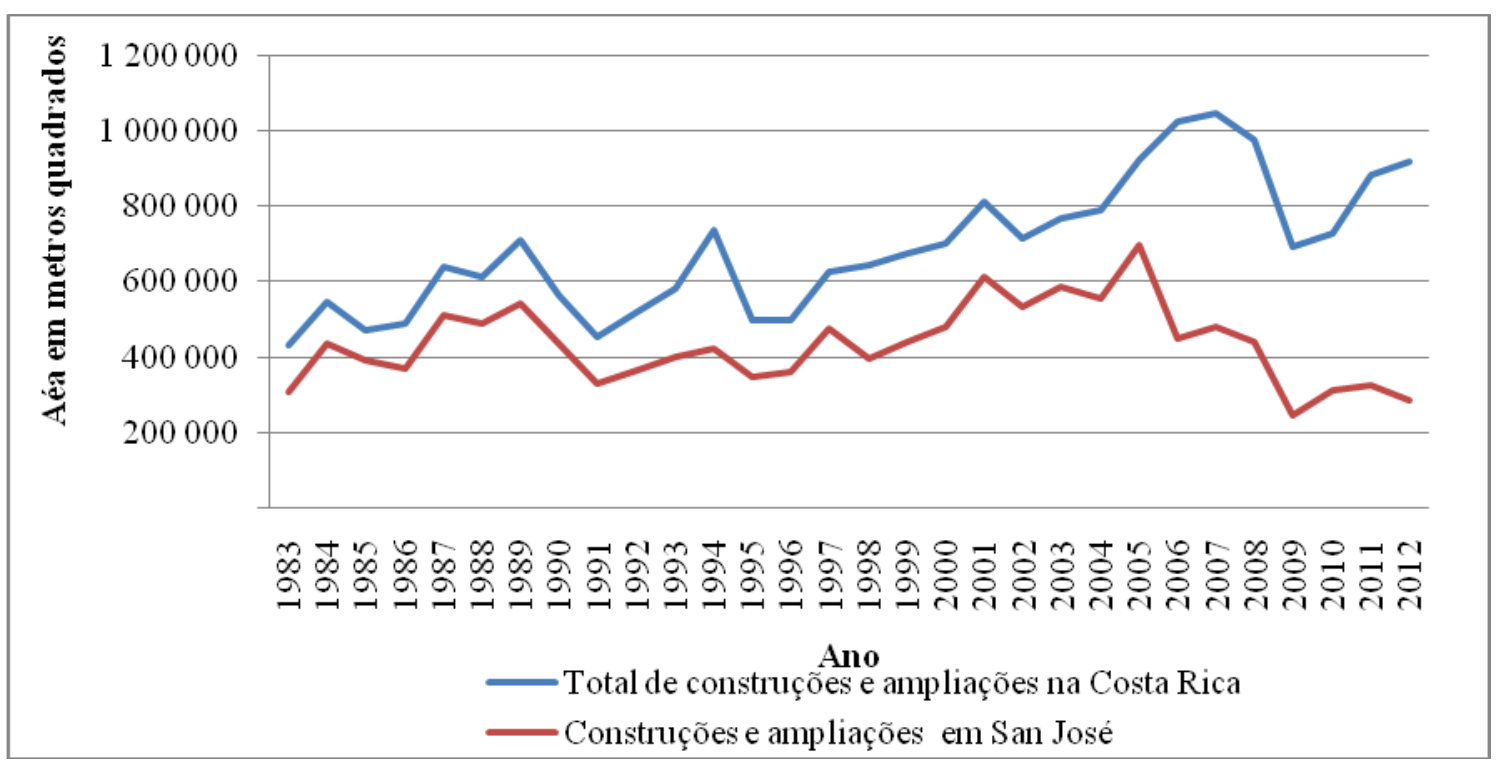

Figura3. Área de construções e ampliações de moradias em metros quadrados no município San José entre 1983 e 2012 .

Fonte: INEC, C02. Área (m2) enconstrucciones y ampliaciones. Província, tipo y destino, 1983-2012.

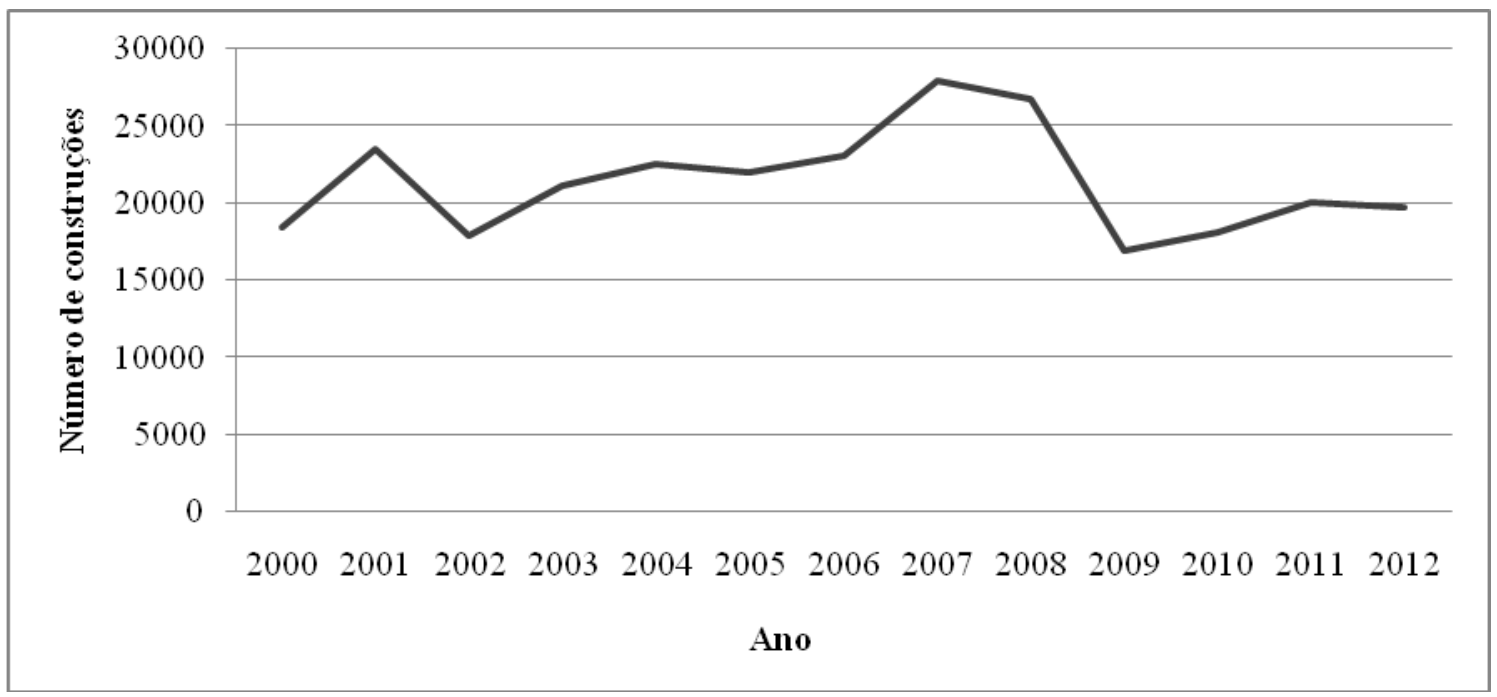

Figura4.Número de construções residenciais (moradias e apartamentos) entre 2000 e 2012 na Costa Rica.

Fonte: INEC, C3. Número de construccionesresidenciales y valor enmiles de colones, según área en metros cuadrados y año: 2000-2012.

Esses padrões respondem a oscilações na economia mundial. A partir de 2008 e 2009 o número de construções sofreu uma queda devido à crise econômica, mas a atividade se recuperou nos seguintes quatro anos, embora não com a mesma intensidade dos anos anteriores. Segundo Byram (2013), Presidente delPuesto de Bolsa del Instituto Nacional de Seguros e da Sociedad de Fondos de Inversióndel Instituto Nacional de Seguros, esse padrão coincide com o problema das hipotecas Sub 
Prime $^{1}$ nos Estados Unidos que começou no final de 2007 e cujo clímax foi em 2008 e 2009². Muitos estadunidenses faziam investimentos em propriedades na Costa Rica e outros países e, com a crise das hipotecas, perderam suas casas e reservas pessoais deixando de investir no exterior. Isso explica a queda abrupta no número e área de construções em geral, tanto no Litoral como na GAM. A Figura 5 evidencia os prédios abandonados, loteamentos fechados e casas de luxo no litoral Pacífico costarriquenho, cujas construções ficaram inacabadas e não foram vendidas por falta de compradores.
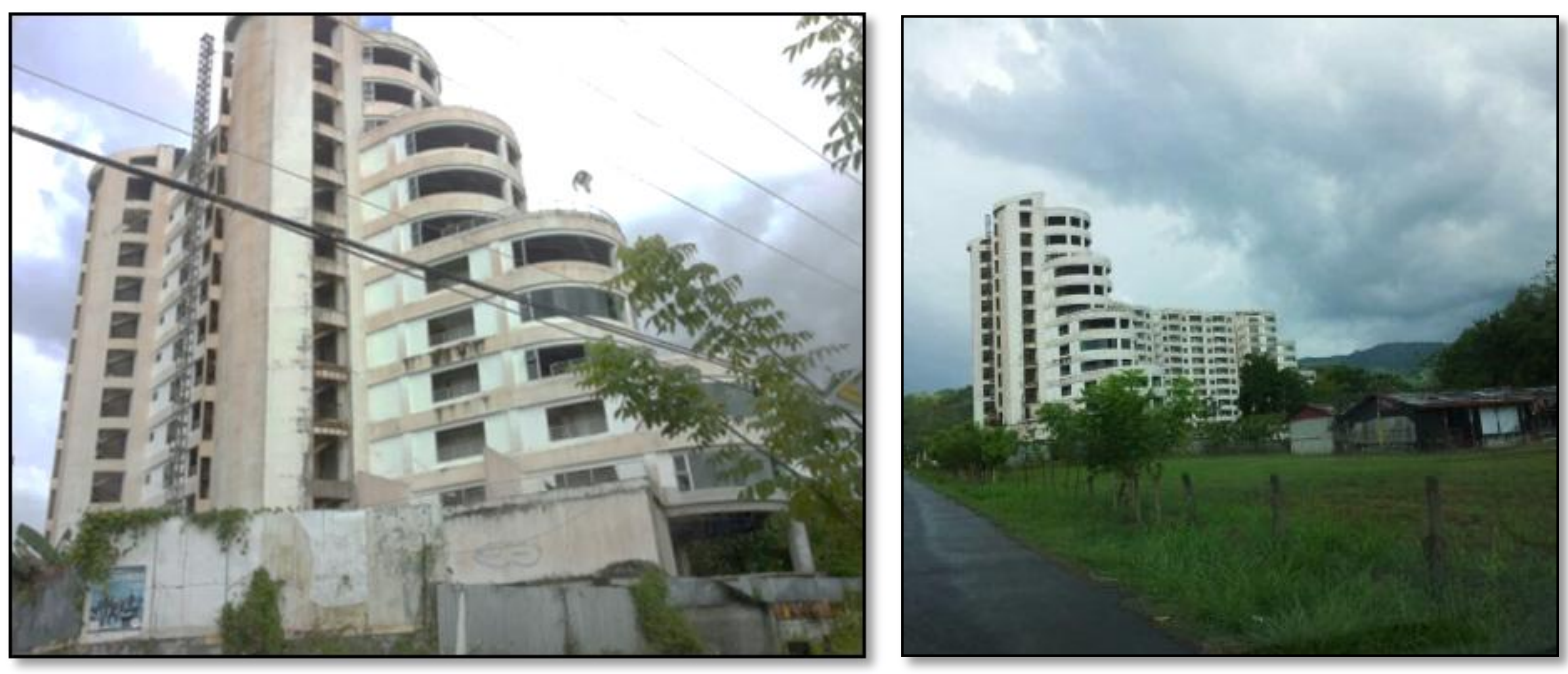

Figura5.Prédios abandonados na praia Jacó, no litoral Pacífico da Costa Rica, devido à recessão de 2008.Fonte: Acervo do autor, 2010.

Para entender estas flutuações no mercado imobiliário é interessante propor uma comparação com um amplo recorte histórico para ressaltar estas dependências. Por exemplo, é importante ressaltar que a economia do país, desde sua condição como colônia, teve que sofrer as consequências das crises internacionais vinculadas às relações capitalistas. Desde que o território formou parte das colônias espanholas e posteriormente se inseriu no mercado mundial como agroexportador, essa condição de

\footnotetext{
${ }^{1}$ As hipotecas Sub Prime são um tipo de hipoteca para moradias e estão voltadas a clientes de escassa solvência e, portanto, com um maior risco de não saldar suas dívidas. Os juros são mais elevados que os empréstimos.

${ }^{2}$ Os imóveis começaram a incrementar seu valor devido a uma percepção do mercado fomentada pelos diferentes participantes (incorporadoras, vendedores, compradores e corretores de imóveis, entre outros). As incorporadoras começam a investir e construir moradias com preços abaixo do mercado. Os devedores, ao perceber a situação, abandonaram suas dívidas e seus imóveis e entraram em foreclosure (execução hipotecária). A crise se agravou porque os bancos e os fundos imobiliários que tinham essas hipotecas entraram em crise e em bancarrota.
} 
dependência econômica o caracteriza. A crescente importância do crédito nas transações agrícolas impulsionou o surgimento do mercado imobiliário ${ }^{3}$ posteriormente propiciou-se a criação dos primeiros bancos no território desde a segunda metade do século XIX. Com a inserção dos bancos privados e internacionais desde 1947 o mercado imobiliário foi se transformado em uma inversão viável para o capital globalizado. Embora não seja o objetivo deste artigo apresentar os detalhes das respostas do setor imobiliário a cada crise econômica ao longo da história do território, sim exemplificam-se as respostas do setor para as mais recentes tendências econômicas a partir de 2008.

Essa última crise econômica de 2008 nos Estados Unidos, especificamente afetando o mercado imobiliário, também afetou a Costa Rica e deixou muitos projetos abandonados. Segundo Byram (2013), a recuperação iniciou quando o mercado local se reativou devido aos bancos que voltaram a financiar casas, condomínios e centros comerciais. Esse efeito também se visualizou na Inversão Estrangeira Direta ${ }^{4}$ (IED) que diminuiu em 2008, na maioria das atividades e especificamente na atividade imobiliária. Posteriormente em 2012 o mercado se recupera e registra um aumento tanto nessa atividade como nos serviços, principalmente.

Atualmente, a política de repovoar a cidade $^{5}$ é favorecida pelo plano regulador que promove a construção de prédios para moradias. Neste contexto, o padrão geral do número de construções nos últimos doze anos mostra que as construções residenciais apresentam aproximadamente mais do dobro do número de construções de comércio, indústria, serviços e outros. Entre 2011 e 2013, a prefeitura de San José registrou um padrão constante no ritmo de solicitações mensais de licenciamentos de construção na capital com uma média de 70 por mês. Conforme continue esta tendência de construção, a cidade tornar-se-á mais atraente, segundo Gonzalo Delgado, presidente da CámaraCostarricense de Construcción. O processo de repovoamento vai desencadear a demanda de novos e renovados

\footnotetext{
${ }^{3}$ O surgimento do mercado imobiliário propiciou mudanças nas atividades econômicas assim como o parcelamento do solo urbano. A cidade "sustenta relações de produção e de propriedade" (LEFEBVRE, 2006, p. 46) e essa nova dinâmica da propriedade imobiliária responderá às novas relações de produção, os novos mercados e assim determinará a magnitude e direção da ação expansiva territorial.

4 Inversão Direta Estrangeira é a inversão de capital ao longo prazo num país estrangeiro com o propósito de internacionalizar a economia.

${ }^{5}$ Programa de Regeneración y Repoblamiento de San José, No 31730-MIDEPLAN-MIVAH, 4 de febrero de 2004.
} 
comércios no setor, o que também impulsiona as construções e licenciamentos para esse setor. Estamos observando como os arredores ao centro de San José estão sendo repovoados como, por exemplo, acontece com o intenso processo de verticalização residencial nos arredores do Parque Metropolitano La Sabana, parque muito próximo aos distritos centrais da Capital (Figura 2).

Entre março de 2012 e fevereiro de 2013 foi tramitado 1,9 milhão de m2 de construção nos municípios da GAM, o que implica um aumento de 15\%. 0 aumento foi principalmente atribuído aos novos condomínios já que em 17 municípios se registrou uma queda na construção de moradias individuais. (SALAZAR, 2013a).

Entrando na segunda década do século XXI, o incremento da área construída entre 2010 e 2011 foi de 152.404 m2, no entanto entre 2011 e 2012 diminuiu para 38.170 m2. A província San José passou então a apresentar um total de 920.138 m2de construções em 2012. (BOLETIN ANUAL, ESTADÍSTICAS DE LA CONSTRUCCIÓN, INEC, 2012).

A figura6 registra que a construção de apartamentos, em metros quadrados, apresenta flutuações entre 2001 e 2010, com um auge considerável a partir de 2006. Esse rápido crescimento foi induzido por um grupo de investidores que aproveitou as modificações na lei de propriedade horizontal que possibilitou a construção de condomínios na GAM. Outro grupo de investidores desenvolveu projetos no litoral Pacífico, os quais respondem a uma demanda imobiliária estrangeira intensificada com o auge do turismo. 


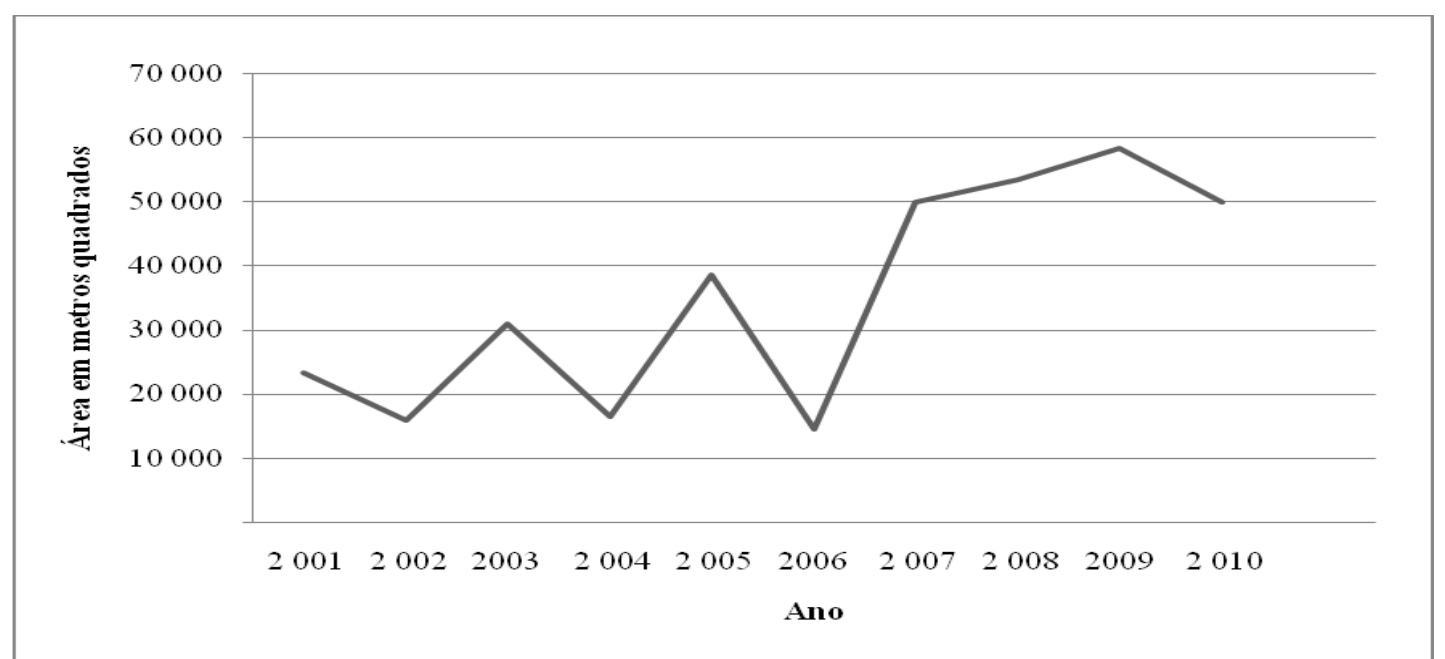

Figura6.Área em metros quadrados de construção de apartamentos no município San José entre 2001 e 2010. Fonte: INEC, C4. Construcción de viviendas y apartamentos, por permisos, obras, área y valor. Segúnlocalidad, 2001-2011.

Embora a quantidade de metros quadrados tramitados em 2013 diminuiu em 3\% comparado a 2012, o setor de moradias, que representa $40 \%$ do total de construções, aumentou em relação a 2012 . Em 2013 se registrou um aumento de 40\% na construção de condomínios e a construção de casas aumentou 9\%. (SALAZAR, 2013b).

\section{Diferenças no valor de uso e valor de troca no mercado imobiliário local}

No centro de San José, nos 5 primeiros distritos centrais Catedral, Hospital, Merced, Carmen e Mata Redonda, considerados o "coração da capital”, se concentram $42 \%$ dos novos imóveis do município San José. O setor do Parque Metropolitano La Sabana (Mata Redonda) registrou a maioria das obras em 2013 (RODRÍGUEZ, 2013) (Figura 7). 


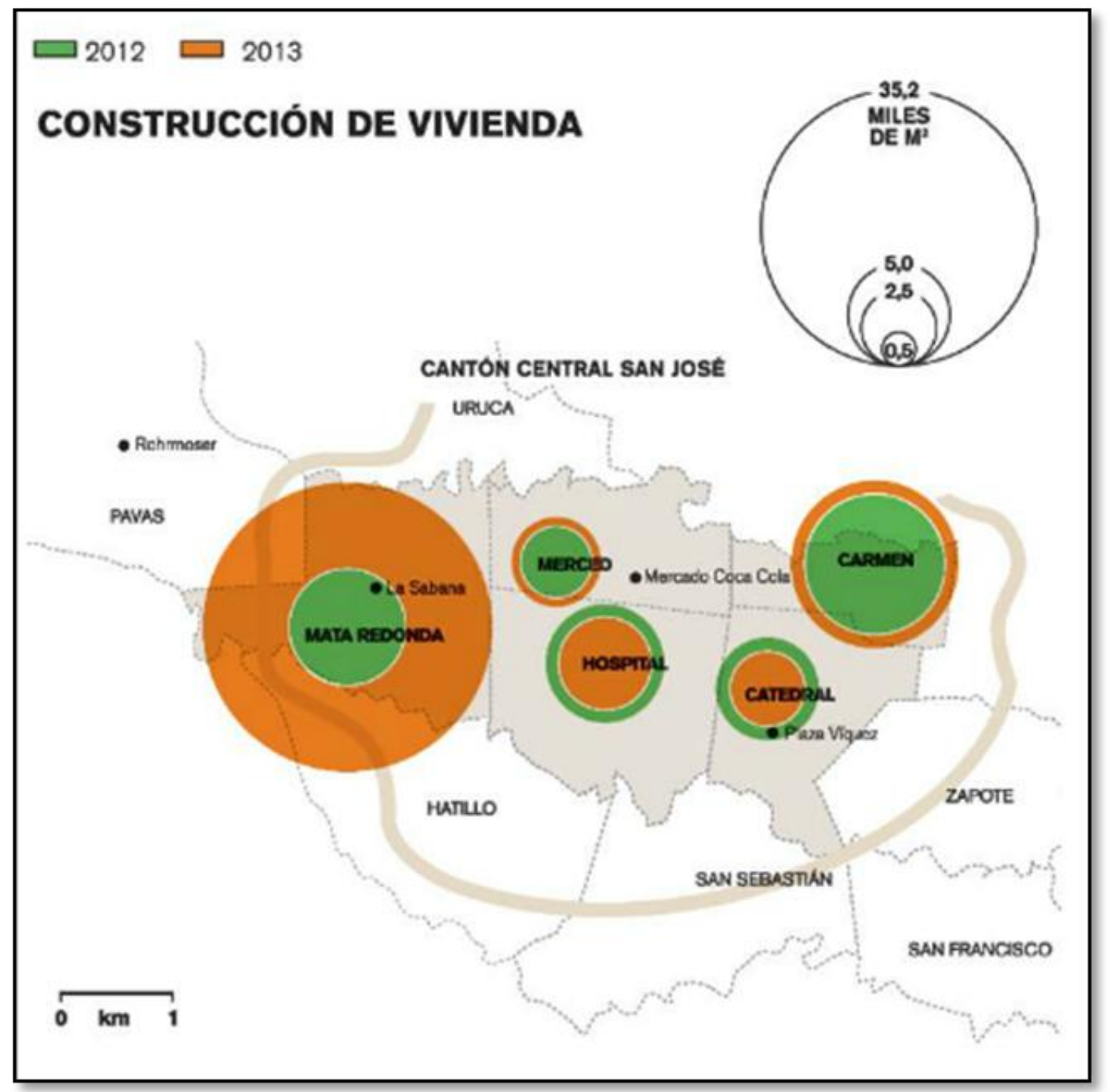

Figura7.Metros quadrados de construção nos cinco distritos de San José entre 2012 e abril de 2013.

Fonte: RODRÍGUEZ, 2013.

Este setor do país continua sendo preferido pelos compradores e comerciantes desde o início do século XX, pelo seu fácil acesso e pelo acesso aos meios de consumo coletivo que agem como um ímã para os investimentos. Os primeiros 4 distritos da capital, continuam apresentando os preços mais elevados do Valle Central desde inícios do século, o que é um atrativo para os atuais investidores de prédios de apartamentos ${ }^{6}$.

\footnotetext{
${ }^{6}$ Embora o aceite deste novo conceito de moradia vertical vem aumentando, tem sido um processo lento devido a fatores como a falta de confiança nas novas tecnologias antissísmicas e também devido ao forte desejo da população de estar em contato com um jardim ou terra de cultivo.
} 
O jornal, La Nación, informou na quarta semana de abril de 2013, que 50 projetos de moradia na GAM, estavam à venda, pré-venda ou construção. A maioria desses projetos está localizada na província de San José e nos municípios de San José e também Santa Ana e Escazú, os quais são lugares associados à localização de residências ou torres de alto padrão. Aqui se exemplifica que a localização exerce uma grande influência na determinação dos preços da moradia. Isto significa que a utilidade dessa mercadoria não é apenas definida pelas suas características internas e acabamentos, enquanto construção. O valor de uso também é dado pela sua articulação espacial com os outros objetos imobiliários. Segundo Queiroz (1981, p. 37), o que é vendido é “[...] um ticket de participação no consumo dos objetos imobiliários.”.

Nestes distritos e na área circundante ao Parque Metropolitano La Sabana a renda diferencial é paga pelos indivíduos ou empresas em vista do superfaturamento que a localização privilegiada lhes proporciona.

Flávio Villaça (1998) concorda que o fundamental na determinação do valor do lote urbano é a localização. Segundo ele, a terra urbana tem valor como qualquer mercadoria e depende da localização. A localização se interpreta como um valor de uso produzido e não dado pela natureza. Depende do papel que o espaço urbano circundante desempenha nas relações sociais da cidade. No caso do capital fixo incorporado à terra (investimentos públicos), esse apenas contribui a uma parte da valorização. No que diz respeito à distância entre centro e seus arredores, o preço da terra pode variar e, portanto, não existe renda diferencial da terra urbana. Cada localização é única no espaço e não pode ser reproduzida. Não se podem reproduzir dois pontos com as mesmas características no espaço. A infraestrutura pode ser reproduzida pelo trabalho humano. No entanto, a localização, na sua forma pura que está ligada aos tempos e custos de deslocamento, não pode ser reproduzida. Segundo Villaça (1998), o preço da terra urbana depende do valor da terra-localização (a expressão monetária do tempo de trabalho socialmente necessário para produzi-la), no entanto ele coloca como ponto fundamental a metropolização que influi na produção e consumo diferenciado da mercadoria. 
Por outro lado, Singer (1982) expõe que o mercado imobiliário tem a característica, diferente do mercado de produtos do trabalho humano, já que os preços tendem a ser determinados pelo que a demanda estiver disposta a pagar em função da acessibilidade aos locais de interesse (trabalho, escolas, comércio, lazer, entre outros). Nesse contexto, se entende como certas empresas geram superlucro devido às vantagens de localização (ou também devido ao desenvolvimento de tecnologias para a construção civil ou ainda a atração de mercado através da propaganda) e também de acordo com suas vantagens específicas dependendo dos segmentos aos quais está direcionado o projeto.

A diferença de preços também pode ser entendida com o conceito de renda de monopólio, que pressupõe uma localização privilegiada que lhe permite estabelecer preços acima do valor das mercadorias, como, por exemplo, a localização de altos segmentos sociais no bairro Rohrmoser, no oeste do Parque Metropolitano La Sabana (Figura 2). No caso do mercado imobiliário nos arredores deste parque, a demanda está disposta a pagar até USD 2500 pelo metro quadrado, o que revela um dos preços mais elevados, enfatizando e mantendo a preferência pela centralidade constatada desde 0 período colonial. Segundo Singer (1982), poder-se-ia supor que a renda de monopólio é um caso extremo da renda diferencial, já que a primeira lhe permite cobrar preços acima dos que a concorrência normalmente apresenta no resto do mercado.

A relação entre a reprodução do capital fundiário e a forma vertical da construção muito próxima ao centro de San José pode relacionar-se com duas hipóteses propostas por Souza (1994) para o caso brasileiro. Em primeiro lugar, a verticalização voltada para a elite se dá em áreas já valorizadas nos arredores do Parque Metropolitano La Sabana (ver figura 2), que estão dotadas de equipamentos urbanos. Nesses lugares se gera um mútuo processo de valorização, a partir dos primeiros edifícios construídos. O segundo ponto corresponde aos terrenos dessa área de estudo, que são bastante valorizados, gerando demanda na construção de edifícios de muitos andares e de alto padrão para "diluir" os custos na fração ideal.

Nesse contexto, cabe destacar o papel importante dos especuladores e dos donos da terra. Cabe ressaltar a importância dos proprietários dos terrenos, especialmente como especuladores, já que as 
reservas de terra controlam o mercado e a direção da expansão urbana. As reservas de terras agrícolas ou cafezais, nos lugares mais acessíveis e pertencentes a famílias de alto poder aquisitivo, continuam sendo associadas aos bairros da elite, especificamente no oeste do Parque Metropolitano La Sabana (Figura 2). Aqui novos empreendimentos estão substituindo as casas de luxo ou terrenos para construir torres de alto padrão. Nesse caso, os especuladores são os moradores desses bairros de alto poder aquisitivo, que estão antecipando essa nova tendência em determinados pontos da cidade. Estima-se que essa tendência abarque mais terrenos que uma vez pertenceram à família Rohrmoser (Figura 2), sendo cafezais desde o século XIX e XX. Muitos já venderam suas propriedades para dar lugar aos novos projetos (Figura 8), no entanto outros continuam morando nos arredores dos novos projetos, provavelmente esperando uma oferta atrativa para desenvolver em sua propriedade.

Muitas dessas propriedades estão sendo alugadas e ocupadas por comércio, escritórios, academias, bancos ou consultórios médicos. Outras são demolidas para abrir espaço para o desenvolvimento de torres (Figura 8).
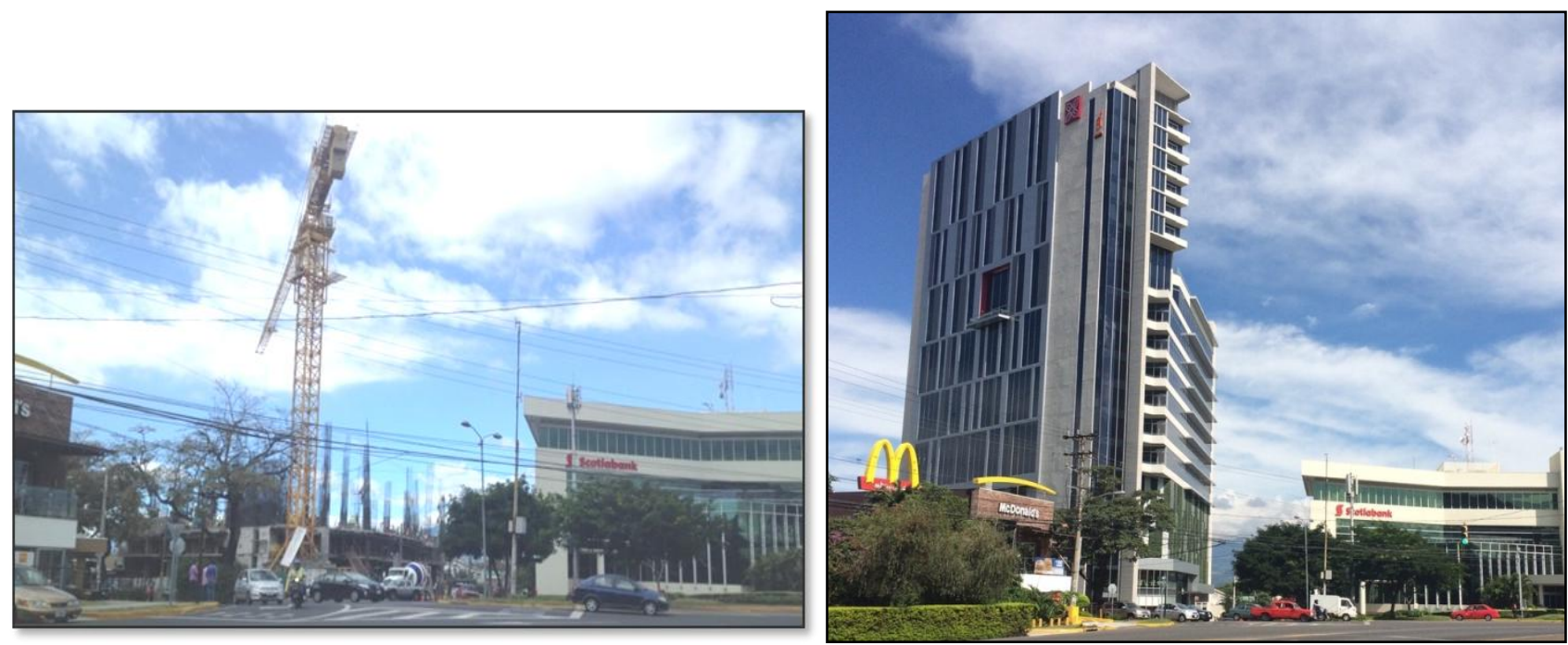

Dezembro 2013.Novembro 2015.

Figura8.Construção do novo empreendimento vertical no bairro de alto padrão, Rohrmoser, no oeste do Parque Metropolitano La Sabana.

Fonte: Acervo do Autor, nov. 2015. 


\section{Fatores que contribuem para o desenvolvimento do mercado imobiliário local}

Para enfatizar a especificidade do lugar desta pesquisa, se pretende realizar uma comparação dos fatores que tem contribuído no desenvolvimento imobiliário local, mas utilizando um amplo recorte histórico. Retomando o referencial teórico de Santos (2012) que apresenta a variável tempo como indispensável na compreensão da relação entre forma, função e estrutura (pois é ele que indica o movimento do passado ao presente) concordo que "cada forma sobre a paisagem é criada como resposta a certas necessidades ou funções do presente.” (SANTOS, 2012, p.73). No entanto, para ilustrar as recentes tendências no mercado, pretendo retomar alguns padrões que ainda se conservam desde o surgimento do mercado imobiliário e os inícios das primeiras transações imobiliárias em San José. O objetivo de aproximar estas temporalidades é de desvendar uma interessante análise de como alguns fatores se mantém ou mudam sua influência no mercado imobiliário.

Em primeiro lugar se desvenda como as desvantagens econômicas e locacionais que o território da Costa Rica apresentava no período colonial, atualmente resultam fatores positivos que posicionam o país como um destino atraente para o turismo, para realizar investimentos imobiliários e inclusive para morar. Essa mudança se deve à configuração de fatores que, no contexto do passado, eram interpretados como fatores negativos, mas que atualmente são utilizados a favor e inclusive vendidos como mercadorias no marketing imobiliário. Por exemplo, no período colonial se considerava desfavorável a localização afastada do território no extremo sul do istmo, com uma topografia de difícil acesso, um clima inclemente, florestas impenetráveis, vulcões ativos e até agrupações de indígenas agressivos. Atualmente a localização geográfica é um dos principais atraentes incluindo a proximidade com o mercado estadunidense, o clima favorável ao longo do ano sem temperaturas extremas, diversos destinos turísticos atraentes como praias, vulcões, bosques e biodiversidade em geral (Figura 9).

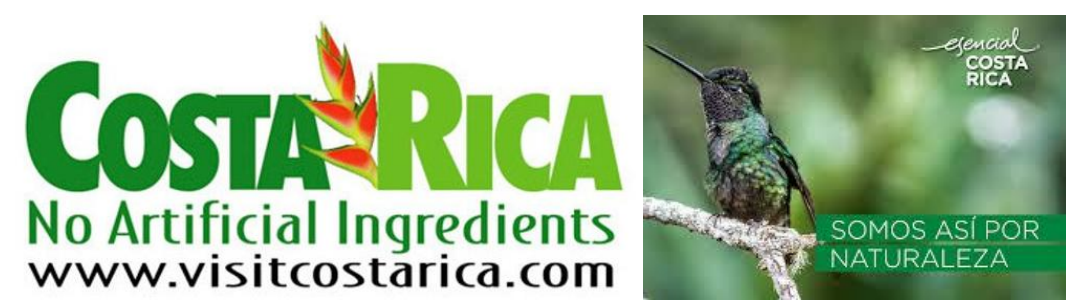

Figura9.Natureza utilizada como propagando pelo estado costarriquenho. 
Fonte: www.visitcostarica.com Aceso em: novembro 2015.

Todas essas são características utilizadas pela propaganda que se apropria da natureza e a coloca como mercadoria que pode ser adquirida pelos compradores dos imóveis. Essas tendências de apropriação da natureza para vendê-la lembram os objetivos que tinham os europeus ao incursionar no território da América Central no período colonial, com o intuito de procurar recursos para exportar e vender. 0 nome Costa Rica inclusive fez alusão a esses recursos que podiam ser consumidos pelo mercado internacional (ouro e produtos agrícolas como cana de açúcar, cacau e madeira). No século XXI continuamos sendo testemunhas de como o território, natureza e paisagem são vendidas para impulsionar o mercado imobiliário. (Figura 10).
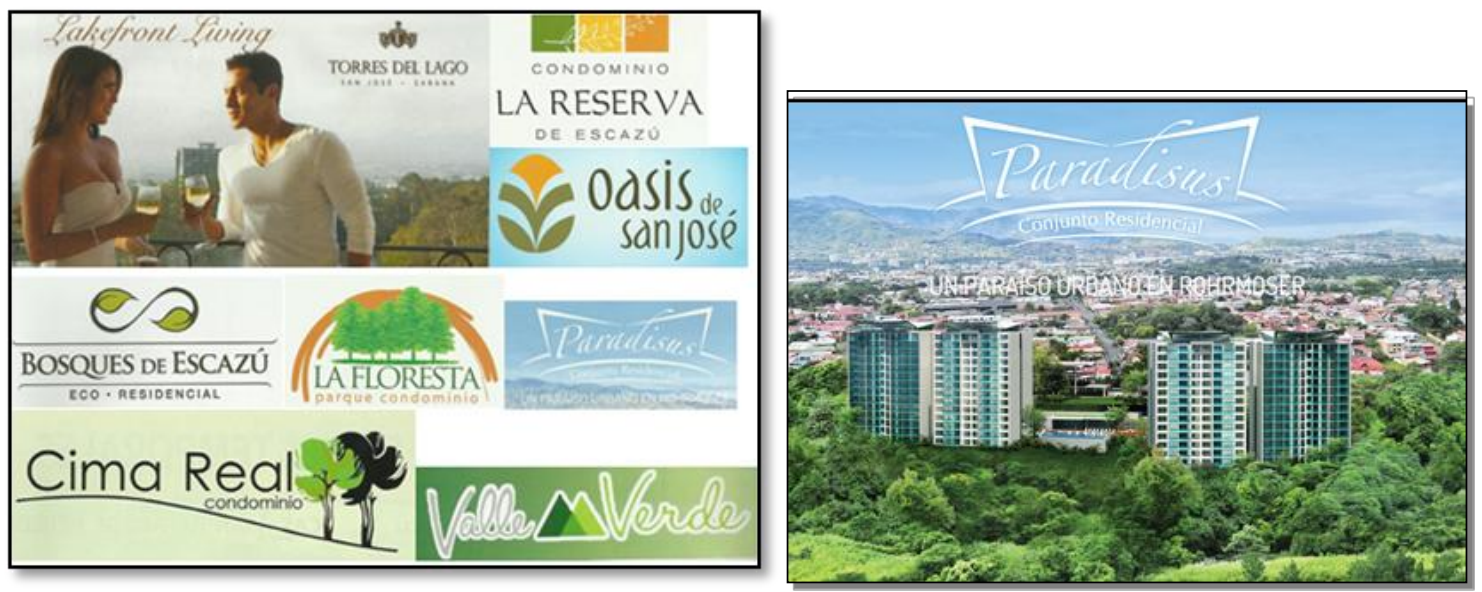

Figura10.Exemplos de propaganda utilizando a natureza como mercadoria.

Fonte: Acervo do autor, 2013.

Continuando com os fatores que contribuem para o desenvolvimento do mercado imobiliário na Costa Rica, nos Estados Unidos existem fatores que propiciam o investimento no exterior, como, por exemplo, a insegurança depois do dia 11 de setembro de 2001, a dinâmica do setor imobiliário e as restrições no sistema de segurança social. A confabulação desses fatores tem estimulado o auge no mercado imobiliário na Costa Rica.

Como outro fator positivo, destaca a característica do mercado consumidor estrangeiro na Costa Rica o qual se distingue por ser de alto poder aquisitivo, pertencente à faixa etária entre 50 e 60 anos, com a 
possibilidade de viajar a um destino sem conflitos bélicos, desfrutando de qualidade vida e com reserva econômica suficiente para alcançar a aposentadoria, tendo expectativas de adquirir uma segunda moradia para ser usada nas férias. (ROMAN, 2008). Outro setor de investidores são os chamados "baby-boomers", com um menor poder aquisitivo e que consideram a Costa Rica como um destino onde podem garantir um estilo de vida adequado quando estiverem aposentados. Esse mercado estadunidense abrange cerca de 75 milhões de pessoas, o que representa um alto potencial de investimento na Costa Rica. Essa população procura não necessariamente se localizar no litoral, onde o valor por metro quadrado é mais alto, mas está disposto a investir no desenvolvimento de cidades intermédias ou propiciar "um novo dinamismo na região central do país." (ROMÁN, 2008).

Para os estrangeiros, Costa Rica continua sendo um destino atraente para o investimento apesar da inflação imobiliária e o encarecimento dos imóveis. Em 2008 se registrou uma relação de preços de três por um com relação ao seu país de origem. Esse fator atraiu uma grande quantidade de participantes nacionais e internacionais, como, por exemplo, incorporadores, corretores de imóveis, escritórios de advocacia, empresas de seguros, empresas construtoras e uma grande quantidade de subcontratantes da indústria da construção civil.

A liquidez no sistema financeiro, a tendência na queda das taxas de juros e as expectativas de uma menor inflação fomentam o crescimento das carteiras hipotecárias dos bancos para a população nacional com ingressos médios e altos. Detalhando esse aspecto, cabe destacar que as taxas de juros diminuíram para 14\% em setembro de 2012 e se estabilizaram em 10\% entre abril e junho de 2013. Em 2013, a taxa básica de juros esteve em 6,55\%, o menor valor nos últimos cinco anos. A partir de 2009, a taxa de juros de empréstimos para construções apresenta uma queda e se estabiliza em 15\% nos bancos estatais em 2013 e por volta de $20 \%$ para os bancos privados e entidades financeiras não bancárias. (Banco Central de Costa Rica, 2013b).

Em 2011, o setor financeiro impulsionou o crédito para o setor de construções de moradias, o que permite evidenciar o papel ativo do Estado no mercado imobiliário. Segundo Gonzalo Delgado, presidente da CámaraCostarricense de laConstrucción: "Loscostarricensestienen que estar tranquilos, 
hay crédito y condiciones favorables de acceso" (SALAZAR, 2013a), embora em 2014 se evidenciasse na média e em eventos como feiras imobiliárias, que muitos projetos residenciais são inacessíveis para a maioria do segmento médio. (Figura 11).

INVESTIGACIÓN DE FUPROVI SENAALA QUE OFERTA INMOBILIARIA NO SE AJUSTA A INGRESO DE HOGARES PROMEDIO

Precio de casas lleva al fracaso planes de crédito a clase media

POR DIEGO BOSQUE G. / diego.bosque@nacion.com - Actualizado el 10 de septiembre de 2014 a: $12: 00$ a.m.

- Leyes creadas para facilitar compra de vivienda no eliminaron el problema existente

- Desarrolladores aseguran que costos operativos impiden hacer mejores ofertas

Figura11.Título de artigo publicado no jornal La Nación.

Fonte: BOSQUE, Diego. Precio de las casas llevaalfracaso planes de crédito a clase media. Disponível em: http://www.nacion.com/archivo/Precio-fracaso-creditos-clase-media_0_1438256220.html. Acesso em: 06 jan.

2015.

O objetivo dos produtos creditícios e das reformas na legislação é oferecer uma alternativa para que este segmento social tenha acesso ao crédito embora se evidencie que os preços dos imóveis parecem fora do alcance do poder aquisitivo dos segmentos médios costarriquenhos.

Entre esses planos está a lei assinada pela ex-presidente Laura Chinchilla, no dia 30 de julho de 2013, para fixar a taxa de juros dos empréstimos para moradias, nos primeiros oito anos. (RODRÍGUEZ, 2013a). Atualmente os bancos oferecem créditos com taxa fixa com o máximo de três anos e a nova legislação pretende diminuir a taxa de juros.

O evento imobiliário ExpoCasa y Decoración ${ }^{7}$ é uma feira anual que conta com a presença de diversos agentes produtores do espaço urbano, públicos e privados, relacionados ao financiamento como, por exemplo, instituições financeiras entre bancos públicos, privados e entidades financeiras não bancárias

\footnotetext{
${ }^{7}$ Evento imobiliário onde participam mais de 30.000 visitantes, 84 incorporadoras, 76 empresas de decoração e se estimula a realização de negócios no setor imobiliário.
} 
creditícias e de poupança e crédito, o que permite que a população tenha acesso às diferentes opções imobiliárias e creditícias para facilitar os negócios.

Nesta Feira do mês de agosto de 2013, a ex-presidente Laura Chinchilla manifestou que percebeu os impactos da nova legislação e os instrumentos que beneficiam os setores mais vulneráveis e a classe média do país. A nova legislação e o desenvolvimento de novas ferramentas financeiras tem pretendido oferecer um respaldo a determinados grupos sociais como, por exemplo, os jovens, mulheres chefes de família, idosos e pessoas com deficiências, no entanto, no mesmo evento em 2014, o público apontou que as ofertas residenciais não atendiam as necessidades dos segmentos médios.

A participação dos bancos locais tem sido fundamental no crescimento da oferta imobiliária na GAM desde 2003. (ROMÁN, 2008). De forma paralela às mudanças na legislação, constantes inovações nos programas de crédito hipotecário também têm facilitado o auge do mercado imobiliário. Por exemplo, o Banco de Costa Rica, um dos maiores em crédito para moradia, lançou um plano para crédito com uma taxa fixa de $10 \%$ nos primeiros 5 anos e depois variável. Essa estabilidade traz tranquilidade para as famílias que têm créditos de moradias com taxas variáveis e amplia a possibilidade para que outros segmentos tenham acesso ao crédito. Nesse contexto, segundo Gerardo Corrales, gerente do BAC San José: "La prima ${ }^{8}$ enmuchos casos esel principal obstáculo." (RODRÍGUEZ, 2013c).

Existem alternativas oferecidas, como por exemplo, o tipo de moeda utilizada para o empréstimo. Na ExpoCasa y Decoración 2013 se estimou que $75 \%$ do financiamento seria em colones (moeda local). 0 Banco de Costa Rica e o Banco Popular ofereceram $75 \%$ dos créditos em moeda local e o Banco Nacional ofereceu 80\% em colones também. MynorRetana, diretor da Banca Hipotecária del Banco Nacional afirmou o seguinte:

\footnotetext{
Promovemos el crédito encolones y para ellosdiseñamosun esquema de financiamiento donde es más atractivo que en dólares. Además, se invitará a losdeudores de viviendaen dólares a que trasladensus saldos a colones. (RODRÍGUEZ, 2013b).
}

\footnotetext{
${ }^{8}$ A tradução de "prima" para o português é entrada.
} 
O motivo para oferecer créditos em colones se justifica, pois a maioria dos créditos está outorgada a um prazo de 20 e 30 anos para famílias cujos ingressos são principalmente em colones. Rodrigo Elliot, gerente de ProductosActivos de DaVivienda, afirma que as diferentes entidades financeiras estão selecionando os clientes com maior cautela. Para isso, utilizam ferramentas que simulam cenários de variações no tipo de câmbio e nas taxas de juros em dólares e assim reduzir o fator de risco de endividamento. (RODRÍGUEZ, 2003b).

ExpoCasa y Decoración 2013 revelou que o ingresso mínimo para financiar casas para a classe média são $700.000^{9}$ colones. 0 montante mínimo para adquirir uma moradia para o segmento social médio é de 55.942.700 ${ }^{10}$ colones. (GUTIÉRREZ, 2013). Os resultados deste evento em 2014 revelaram que o poder aquisitivo da população dos segmentos médios não é suficiente para poder comprar uma propriedade.

Nesse contexto sobre a participação do setor financeiro, outros recursos de investimento provêm do exterior principalmente para os projetos nos litorais. Com a chegada da banca internacional na Costa Rica, através de aquisições de bancos locais, se intensificou a concorrência local e se ampliaram as possibilidades de oferecer crédito hipotecário a investidores não residentes e frequentemente clientes destes bancos globais. Este é um exemplo de outro agente interagindo nas relações do mercado imobiliário.

Estes produtos creditícios analisados permitem ver como se pretende facilitar o desenvolvimento do mercado imobiliário e ampliar a oferta residencial para os diferentes segmentos sociais, especificamente o segmento médio. Os novos padrões imobiliários estão sendo desenvolvidos de maneira paralela às mudanças na legislação e às táticas de marketing dos atores financeiros públicos e privados. A interação dos diversos agentes tem permitido ampliar a oferta e abranger um maior setor população do que em anos anteriores, no entanto, a população se queixa de que as ofertas continuam estando fora de seu alcance. Assim mesmo cabe ressaltar que as diferenças percebidas nas tendências

\footnotetext{
${ }^{9}$ Equivale a USD 1.277,29 ou BRL 3.450,73. Data cotação utilizada: 06/01/2015.

${ }^{10}$ Equivale a USD 96.604,54 ou BRL 260.986,83. Data cotação utilizada: 06/01/2015
} 
demográficas (o tamanho das famílias, os objetivos dos diferentes grupos etários, e a maior inserção das mulheres no mercado laboral nas últimas décadas) têm influenciado tanto nas ofertas residenciais, como nos produtos creditícios oferecidos assim aumentando a possibilidade para ter acesso a estas alternativas.

\section{Fatores que limitam o desenvolvimento imobiliário local}

A primeira limitante exposta é a escassez de mão de obra. Isso se evidencia devido às mudanças nos fluxos migratórios a partir das modificações na Ley de Migración. Isto aconteceu na agricultura e agora com os projetos imobiliários. A escassez de mão de obra ocorre no nível operativo e está também relacionada à escassez de engenheiros, mestres de obras e auxiliares de construção. As empresas construtoras têm começado a reduzir a relação mão de obra e o custo total do projeto de $30 \%$ a $20 \%$ mediante o uso intensivo de máquinas e inovações tecnológicas. (ROMÁN, 2008).

A disponibilidade de novas tecnologias para a construção ampliou as possibilidades de construção especificamente desde o período Republicano com a introdução do concreto armado no século XX. Atualmente máquinas e equipamentos para a construção vertical impõem novas necessidades às empresas construtoras na Costa Rica para cumprir com os contratos e os prazos estabelecidos.

A disponibilidade e qualidade dos meios de consumo coletivo são outros fatores que podem limitar o desenvolvimento do mercado imobiliário. Por exemplo, frente aos limites capitalistas do financiamento dos meios de comunicação e de consumo coletivo não rentável, o financiamento público permitiu o desenvolvimento de todas as condições gerais de produção, tanto dos meios de consumo como dos meios de circulação. (LOJKINE, 1997). No entanto, existe uma pressão sobre o Estado para prover meios de consumo coletivo, infraestrutura e cobrir as necessidades relacionadas às diversas instituições públicas. Nesse contexto, o fornecimento de água é imprescindível para obter os licenciamentos para iniciar os projetos residenciais. Com o auge imobiliário, o Estado tem o desafio quanto a infraestruturas para disponibilizar água para as zonas de demanda de novos projetos e de povoados já existentes. 
Outro fator que dificulta o mercado imobiliário se relaciona com os diferentes agentes no setor de construções que assinalam as constantes dificuldades devido ao excesso de burocracia que incrementam os custos para os projetos em até dois anos. A burocracia é um fenômeno que a população tem tido que enfrentar desde o período colonial, quando os licenciamentos relacionados à posse da terra e às propriedades tinham que esperar extensos períodos de tempo enquanto os documentos eram enviados até a Audiencia de Guatemala e, muitas vezes, resolvidos de forma ilícita para acelerar o processo. Nesse caso, a burocracia continua, por outros motivos, freando os procedimentos. Isso acontece especificamente no controle sobre os impactos ambientais devido a dificuldades técnicas e orçamentárias e pelo tempo de revisão dos estudos e processamento dos documentos para obter o licenciamento, o que pode demorar meses e até anos em espera. Muitos projetos, inclusive, estão à venda sem contar com a aprovação dos licenciamentos ambientais, com o intuito de reduzir o tempo de circulação do capital. Diversas prefeituras e instituições desconhecem e questionam licenciamentos e documentos outorgados por entidades reitoras, o que se traduz em demoras e gastos nos orçamentos para tornar a confirmar dados que já foram previamente autorizados.

Grandes investimentos a médio ou longo prazo muitas vezes modificam seus planos e projetos dependendo da realidade local ou necessidade do investidor. Nesses casos os projetos são afetados quando as instituições exigem especificar o uso do solo no final do projeto, impossibilitando eventuais modificações.

Os débeis e insuficientes instrumentos de planificação na Costa Rica, incluindo a não existência de planos reguladores em uma grande quantidade de prefeituras, podem ser considerados vantajosos e desvantajosos também. Por um lado podem ser considerados favoráveis devido à flexibilidade para os que querem investir em áreas onde a obtenção de licenciamentos é complicada permitindo ao investidor desenhar seu projeto adaptado aos seus requerimentos. Por outro lado, a ausência de um quadro regulador põe em perigo o valor dos projetos de longo prazo devido à impossibilidade para o investidor de controlar ou conhecer como se desenvolverá o entorno. (ROMAN, 2008). Essa é a importância de 
entender as consequências das lacunas no quadro legal na hora de realizar uma efetiva planificação urbana.

Outro fator que limita o desenvolvimento imobiliário local é a irregularidade na transferência de bens imóveis, o que propicia a insegurança jurídica da propriedade. Inconsistências em dados básicos no Registro Nacional como tamanho e valor dos imóveis aumentam a preocupação.

Outra limitante para o desenvolvimento do mercado imobiliário são as características da construção civil, que, segundo Jaramillo (2009), atuam como obstáculos na sociedade capitalista e são observados claramente desde a inserção do café na economia costarriquenha e o desenvolvimento urbano. Esses obstáculos que caracterizam o processo de produção são:

1. O período de rotação é excessivamente prolongado desde que se inicia o processo até a obtenção do produto terminado e não é menor que um ano, isto no melhor cenário.

2. O espaço construído é um bem com um preço muito elevado e o número de demandantes que podem ter acesso é reduzido. Neste caso se requer ter acesso a formas de circulação que fracionem os pagamentos ao longo do tempo. O aluguel é uma forma de ter acesso a um imóvel somente por tempo limitado sem ter que investir em grandes quantidades de dinheiro para comprar uma propriedade. A soma de dinheiro é menor que o preço do imóvel e correspondente à porção que vai ser consumida durante esse tempo. (JARAMILLO, 2009). Essa é uma forma de circulação que permite fracionar os pagamentos pelo consumo em períodos de tempo que são acessíveis ao trabalhadores a curto prazo.

3. O longo período de circulação se traduz numa falta de incentivos porque o capital produtivo se imobiliza em tarefas não produtivas, o qual ameaça a continuidade da produção e exige uma acumulação prévia de capital mais elevada que em outros processos de produção, normalmente.

4. Outro obstáculo é o acesso à terra e o fato de que está apropriada individualmente. Em certos casos, o capitalista deve lidar com diferentes terratenentes ou inclusive enfrentar a realidade de escassez de terra devido a algumas formas de propriedade que não se adaptam ao funcionamento capitalista do mercado ou estão tão fragmentadas e se desconhece o dono original. 
5. As oscilações das condições de acumulação são frequentes e vulnerabilizam o processo produtivo. Existem flutuações no suministro e nos preços de insumos, na disponibilidade de mão de obra e na amplitude da demanda.

6. O capital se encontra na construção de um mercado estreito com um preço muito elevado especialmente agora com o novo padrão de moradia vertical em San José.

7. Existem circunstâncias que dificultam a existência de um número suficiente de compradores para os espaços construídos.

Também cabe destacar que a ameaça de uma desaceleração brusca no mercado de moradias nos Estados Unidos limitaria o desenvolvimento na Costa Rica. Se os clientes são do segmento que compram residências em condomínios por USD $500.000^{11}$ ou mais, os efeitos não se sentirão com força já que é uma população com importantes reservas e não precisam de crédito. Se o caso for de investidores menores (USD $100.000^{12}$ a USD $300.000^{13}$ ) que hipotecam sua casa nos Estados Unidos e vêm para a Costa Rica para investir, o efeito seria maior já que terão o acesso ao crédito restringido. Esse é um exemplo de como mais uma vez o mercado costarriquenho tem que responder às dinâmicas internacionais.

\section{Considerações finais}

Neste artigo se desvendaram as principais tendências do mercado imobiliário que têm surgido especificamente desde o auge habitacional durante a primeira década do século XXI.

Comprovaram-se como as flutuações na economia mundial afetam as tendências do mercado imobiliário local incluído o efeito negativo sobre a Inversão Direta Estrangeira. Observou-se como conforme o mercado se recupera, registra-se um aumento flutuante nas atividades imobiliárias.

\footnotetext{
${ }^{11}$ Equivale a CRC 266.525.000,00 ou BRL 1.350.800,00. Data cotação utilizada: 06/01/2015.

${ }^{12}$ Equivale a CRC 53.305.000,00 ou BRL 270.160,00. Data cotação utilizada: 06/01/2015.

${ }^{13}$ Equivale a CRC 159.915.000,00 ou BRL 810.480,00. Data cotação utilizada: 06/01/2015.
} 
Diversos fatores influenciam a utilidades dos empreendimentos residenciais. O seu valor se uso depende da localização e é dado pela articulação espacial com outros objetos imobiliários e meios de consumo coletivo. Esta diferença na renda é assumida pelos indivíduos que estão dispostos a pagar em função da acessibilidade aos locais de interesse.

Posteriormente, utilizando um amplo recorte temporal, analisaram-se fatores que facilitam e limitam o desenvolvimento do mercado. Quanto aos fatores que atraem investimentos, ao contrário do que aconteceu durante o período colonial, quando o território contava com numerosas desvantagens para o desenvolvimento econômico, político e social dos europeus, se corrobora que muitos destes fatores são atualmente vistos de maneira favorável. Por exemplo, a topografia irregular e o clima tropical, atualmente são utilizados a favor do desenvolvimento do mercado imobiliário. As diversas técnicas de marketing que, por exemplo, utilizam a natureza e a paisagem como mercadorias têm apresentado uma crescente importância na publicidade de imóveis.

Os fatores que dificultam os investimentos destacam a escassez de mão de obra, a disponibilidades de novas tecnologias de construção (especificamente antissísmicas), o excesso de burocracia, os débeis instrumentos de planificação e a insegurança jurídica da propriedade. Também se agregam as características da mesma construção civil como, por exemplo, o período de rotação prolongado, os altos preços do espaço construído, o longo período de circulação, o acesso à terra e as oscilações nas condições de acumulação. Outros fatores externos como uma possível desaceleração no mercado de moradias nos Estados Unidos também afetam o mercado imobiliário local.

Entre as recentes tendências que este artigo desvendou está o fato de que os produtos financeiros não são accessíveis para todos os grupos sociais. Os altos preços e os produtos oferecidos impossibilitam que todos os setores sociais possam ter acesso ao novo conceito de moradia vertical embora a legislação e os produtos creditícios estejam aparentemente focados para os setores médios.

\section{REFERÊNCIAS}


BANCO CENTRAL DE COSTA RICA.Bancos Estatales. Tasas de interés para préstamos en moneda nacional para

Vivienda.Disponível

$<$ http://indicadoreseconomicos.becr.fi.cr/indicadoreseconomicos/Cuadros/frm VerCatCuadro.aspx?idioma $=1 \&$ CodCuadro= $\% 20495>$. Acessoem: 14 set. 2013.

BOSQUE, Diego. Precio de las casas lleva al fracaso planes de crédito a clase media. Disponível em:

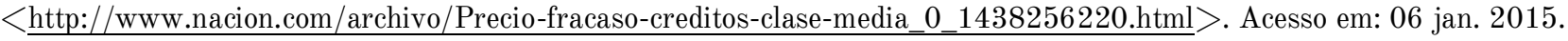

BYRAM, Lemuel. Tendências recentes do desenvolvimento do mercado imobiliário costarriquenho: Entrevista. [Outubro 2013]. San José. Entrevista concedida ao Autor.

CFIA, COLEGIO FEDERADO DE INGENIEROS Y ARQUITECTOS. Comunicado de Prensa: Sector construcción registra decrecimiento del $12 \%$ en el primer semestre. Disponível em: $<$ http://www.cfia.or.cr/noticias.htm $>$. Acesso em 18 set. 2013.

GUTIÉRREZ, Tatiana. Opciones de vivienda para clase media inician en $\$ 100.000$ : Desarrolladores promocionan proyectos en ExpoCasa 2013. La Nación, San José. Disponívelem: < http://www.nacion.com/economia/Bancos-apuesta-creditosvivienda-colones_0_1361063918.html $>$. Acesso em: 14 set. 2013.

IGN. Instituto Geográfico Nacional. Hoja Abra 1:50 000.

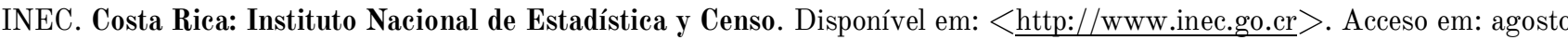
2013.

INEC. BOLETIN ANUAL, ESTADÍSTICAS DE LA CONSTRUCCIÓN, 2012.

ITCR: Investigación del Instituto Tecnológico de Costa Rica. Atlas de Costa Rica. 2008.

JARAMILLO, Samuel. Hacia una teoría de la renta del suelo urbano. (2ed). Bogotá: Universidad de los Andes, Facultad de Economía, CEDE, Ediciones Uniandes, 2009.

LEFEBVRE, Henri. 0 direito à cidade. 4. Ed. São Paulo, Centauro Editora. 2006.

QUEIROZ RIBEIRO, Luiz Cesar de. Espaço urbano, mercado de terras e produção da habitação. In: SILVA, L. A. MACHADO de. (Org.). Solo urbano. Tópicos sobre o uso da terra. Rio de Janeiro: Zahar, 1981.

RODRÍGUEZ, Óscar. Plan de vivienda para clase media queda a voluntad de bancos: Presidenta firmó ley que abarata fondos para comprar casa.La Nación, San José. Disponívelem: < http://www.nacion.com/economia/Uso-clase-mediadependera-banca_0_1357064333.html $>$. Acessoem: 14 set. 2013a.

RODRÍGUEZ, Óscar. ExpoCasa: Bancos apuestan fuerte por los créditos de vivienda en colones: 13 instituciones financieras compitiendo en préstamos. La Nación, San José. Disponívelem: < http://www.nacion.com/economia/Bancos-apuestacreditos-vivienda-colones_0_1361063918.html $>$. Acessoem: 14 set. $2013 \mathrm{~b}$.

RODRÍGUEZ, Óscar. Tres planes de vivienda para clase media avanzan despacio: leyes estarían reglamentadas a fin de año, pero se discuten desde 2010. La Nación, San José. Disponível em: < http://www.nacion.com/economia/planes-viviendaclase-avanzan-despacio_0_1353864618.html $>$ Acesso em: 16 set. 2013d.

RODRIGUEZ, Oscar. La construcción late de nuevo en el corazón de San José. La Nación, San José. Disponívelem: <http://www.nacion.com/archivo/construccion-nuevo-corazon-San-Jose_0_1336466352.html>.Acesso em: 15 nov. 2015. 
ROMÁN, Marcela. Análisis del Mercado Inmobiliario-Hipotecario de Costa Rica.Parte 1: Características y dinámica reciente. Unidad Ejecutora del Programa de Regularización del Catastro y Registro Nacional de la Propiedad Inmueble y su compatibilización con el Registro Contrato de Préstamo BID 1284/OC-CR. Marzo, 2008.

SALAZAR, Camila. Torres de condominios dominan la oferta de vivienda en la GAM. La Nación. San José. Disponível $\mathrm{em}:<\underline{\mathrm{http}}$ //periodico.nacion.com/doc/nacion/la_nacion-22abril2013/2013042201/27.html\#27>. Acessoem: 16 set. $2013 \mathrm{a}$.

SALAZAR, Camila. Vivienda contuvo caída de la construcción en el 2013: Sector creció 20\%, en tanto edificaciones en general bajaron 3\%. La Nación. San José. Disponível em: < $\underline{\text { http://www.nacion.com/economia/empresarial/Vivienda- }}$ contuvo-caida-construccion_0_1387461249.html >. Acesso em: Jan. 2013b.

SANTOS, Milton. Metamorfose do espaço habitado. 6 ed. $1^{\text {era }}$ reimpressão. São Paulo: Edusp, 2012.

SOUZA, M. A. DE. A identidade da metrópole. A verticalização em São Paulo. São Paulo: Huitec, 1994.

SPOSITO, Maria Encarnação Beltrão. Capitalismo e urbanização. São Paulo. Editora Contexto, 2002. 